\title{
Exploring the Effects of Nurses' Family-Work Conflict on Patient Care Quality: A Qualitative Study
}

\author{
Sommaye Namdari (iD) ${ }^{1}$, Ahmad Nasiri (iD ${ }^{1,}{ }^{*}$, Samaneh Nakhaee $\left(\right.$ (D) $^{2}$ and Fatemeh Taheri (D) ${ }^{1}$ \\ ${ }^{1}$ Faculty of Nursing and Midwifery, Birjand University of Medical Sciences, Birjand, Iran \\ ${ }^{2}$ Medical Toxicology and Drug Abuse Research Center, Birjand University of Medical Sciences, Birjand, Iran \\ "Corresponding author: Associate Professor, Medical Toxicology and Drug Abuse Research Center, Birjand University of Medical Sciences, Birjand, Iran. Tel: +98-5632381406, \\ Email: nasiri2006@bums.ac.ir
}

Received 2018 September 06; Revised 2018 November 25; Accepted 2018 December 10.

\begin{abstract}
Background: Nurses need to perform different roles and fulfill different responsibilities. Thus, they experience great levels of strain, which result in conflicts between their family and work. Such conflicts may negatively affect their professional performance. Objectives: The aim of this study was to explore the effects of nurses' family-work conflict on patient care quality.

Methods: This qualitative study was conducted using the content analysis approach. Fifteen nurses (ten females and five males) were purposively selected. In-depth unstructured interviews were held for data collection. The data were analyzed through Graneheim and Lundman's content analysis approach.

Results: The effects of nurses' work-family conflict on patient care quality fell in three main themes, namely reduced mental ability for care provision, low care-providing morale, and damages to professional communications. Each of these themes had two subthemes, which were respectively poor concentration on care provision, impreciseness in care provision, poor job motivation, job dissatisfaction, challenges in establishing relationships with patients, and problems in establishing relationships with other hospital staff.

Conclusions: Family-work conflict negatively affects patient care quality. Thus, appropriate strategies were needed for its prevention and management. These strategies may include job enrichment, job rotation, and in-service continuing education about stress management, time management, and conflict management.
\end{abstract}

Keywords: Family-Work Conflict, Nursing, Healthcare Quality, Patient Care, Qualitative Research

\section{Background}

Work and family are two main parts of human life (1). However, most humans have problems in creating balance between work and life (2). A study reported that $70 \%$ of workers were dissatisfied with their work-life balance and hence, half of them experienced high levels of stress (3). Moreover, the number of workers, who spend most of their time and energy at work and are thus unable to fulfill their household responsibilities is progressively increasing (4). The resultant imbalance is called conflict between family and work (5).

Conflict between family and work is a two-sided problem, which includes both family-work conflict and workfamily conflict. The former happens when familial problems affect the quality of work life and result in reduced ability to perform occupational roles. The latter happens when occupational responsibilities reduce worker's time, commitment, and energy, and thereby prevent him/her from effectively performing his/her familial roles (6).

Nurses also experience family-work imbalances due to shift work in long working hours, heavy workload, numerous contacts with a wide range of patients, workplace violence, and the need for fulfilling a wide range of familial and professional needs (5). Studies show that nurses experience higher levels of conflict compared with other healthcare professionals (7) and hence, conflict is considered as one of the most important global problems in nurs$\operatorname{ing}(8)$.

Conflict between work and family exerts many different negative effects on both work and family, causes workers different levels of stress, and imposes heavy financial burdens on both workers and organizations (3). Both work-family and family-work conflicts are associated with job and life dissatisfaction, job burnout, absences from work, reduced mental health, psychological problems (such as great stress), physical health problems, and reduced quality of work and family life (9). Two studies 
also reported that high levels of work-family conflict can lead to negative consequences, such as job and life dissatisfaction, considerable concern, psychological strains, physical symptoms, depression (10), job burnout $(10,11)$, and marital dissatisfaction (11). Concerns over work-family and family-work conflicts can create barriers to the recruitment of new nurses to the profession, make nurses decide on leaving the profession, and thereby, exacerbate nursing staff shortage (12). All of these problems negatively affect the quality of patient care and endanger patient safety (13).

Despite the importance of conflict between work and family, most previous studies on its effects were conducted using quantitative methods. However, phenomena, which are related to human behaviors, beliefs, and attitudes are mostly subjective and hence, cannot be thoroughly assessed using quantitative research methods. The best approach for studying such phenomena is qualitative research because this type of research provides clearer understanding about poorly known phenomena (14).

\section{Objectives}

The current literature search revealed that no qualitative study had yet been done in this area in the sociocultural context of Iran. Therefore, the present study sought to explore the effects of nurses' family-work conflict on patient care quality.

\section{Methods}

This qualitative study was conducted using the content analysis approach. Study participants were fifteen nurses purposively recruited from two teaching hospitals affiliated to Birjand University of Medical Sciences, Birjand, Iran. Sampling was continued until data saturation. Inclusion criteria were employment in one of the teaching hospitals in Birjand, Iran, willingness to participate in the study, ability to share experiences, history of frequent conflicts, Bachelor's degree or higher in nursing, and a work experience of more than one year.

Data were collected via in-depth unstructured interviews held in a quiet room. Each interview was started using broad open-ended questions such as "Can you explain about one of your work days in hospital?" and "May you explain your experiences of interaction with hospitalized patients?". Based on participants' responses to such questions, probing questions were used to collect more detailed data. The time and place of the interviews were determined based on participants' preferences. The duration of the interviews was 30 to 90 minutes. All interviews were recorded using a tape recorder.
Concurrently with data collection, data analysis was performed through Graneheim and Lundman's content analysis approach (15). Each interview was transcribed word by word and then, the transcript was coded. The codes were categorized to categories, subthemes, and main themes, according to their similarities and differences.

The trustworthiness of the data was established via Guba and Lincoln's criteria, namely credibility, dependability, confirmability, and transferability (16). To ensure credibility, the researchers asked some participants to review the coded texts and established continuous relationships with all participants throughout the study through face-to-face contacts, telephone contacts, short message system, and electronic mails. Dependability was ensured through asking several nurses, who were not included in the study, to check whether the findings conformed with their experiences. All of them confirmed the conformity. For confirmability, all steps of the study were taken under the close supervision of several experienced supervisors. Transferability was also ensured through maximum variation sampling concerning participants' age, gender, clinical experience, and hospital ward.

This study was approved by the Ethics Committee of Birjand University of Medical Sciences, Birjand, Iran (code: IR.BUMS.REC.1396.163). Participants were provided with information about the study aim and the confidential handling of the study data. Their consents were then secured.

\section{Results}

Participants were ten female and five male nurses. Six participants held Bachelor's degree and nine held Master's degree in nursing. Their work experience in different hospital wards ranged from eighteen months to fifteen years and the mean of their age was $33.07 \pm 7.7$.

The effects of family-work conflict on patient care quality were categorized to three main themes of reduced mental ability for care provision, low care-providing morale, and damages to professional communications (Table 1). These themes are explained in the following.

\subsection{Reduced Mental Ability for Care Provision}

This main theme had two subthemes, namely poor concentration on care provision and impreciseness in care provision.

\subsubsection{Poor Concentration on Care Provision}

4.1.1.1. Preoccupation at Workplace with Familial Problems

One of the major concerns of participants, particularly female participants, at the workplace was their preoccupa- 


\begin{tabular}{|c|c|c|}
\hline Main Themes & Subthemes & Categories \\
\hline \multirow{3}{*}{ Reduced mental ability for care provision } & \multirow{2}{*}{ Poor concentration on care provision } & Preoccupation at workplace with familial problems \\
\hline & & Forgetfulness \\
\hline & Impreciseness about care provision & Poor attention to the details of patient care \\
\hline \multirow{5}{*}{ Low care-providing morale } & \multirow{3}{*}{ Poor job motivation } & Intention to leave the profession \\
\hline & & Disinterest in nursing \\
\hline & & Feelings of fatigue and exhaustion \\
\hline & \multirow[b]{2}{*}{ Job dissatisfaction } & Financial problems \\
\hline & & Numerous work shifts \\
\hline \multirow{4}{*}{ Damages to professional relationships } & \multirow{2}{*}{$\begin{array}{l}\text { Challenges in establishing relationships with } \\
\text { patients }\end{array}$} & Improper conduct towards patients \\
\hline & & $\begin{array}{l}\text { Tensions in relationships with patients' family } \\
\text { members }\end{array}$ \\
\hline & \multirow{2}{*}{$\begin{array}{l}\text { Problems in establishing relationships with other } \\
\text { hospital workers }\end{array}$} & Tensions in relationships with colleagues \\
\hline & & Poor relationships with physicians \\
\hline
\end{tabular}

tion with their children. This concern peaked in case of serious familial problems, such as the affliction of children by illnesses. Sometimes, this concern negatively affected patient care.

In case of any familial problem, I'm deeply preoccupied at the workplace with that problem and how to manage my household. Thus, I cannot concentrate on patient care. For instance, my husband wanted to go on a trip and I was very unhappy because the day after that, I had a night shift and there was no body to take care of my child. Then, I was completely preoccupied at work with my child (P.4).

When I feel upset due to a familial problem, I cannot concentrate on my work and cannot pay adequate attention to my patients because I'm preoccupied with the problem (P. 2).

\subsubsection{Forgetfulness}

Preoccupation at the workplace with familial problems could cause forgetfulness for participants and reduce their ability to pay careful attention to patients' needs.

Fatigue due to household activities negatively affects my work. For example, it makes me forgetful about many things. It also negatively affects my memory (P.7).

\subsubsection{Impreciseness in Care Provision}

4.1.2.1. Poor Attention to the Details of Patient Care

Preoccupation with familial problems had prevented study participants from paying careful attention to the details of patient care at work.

Any familial problem, even a minor dispute, reduces my productivity and hence, prevents me from working as effectively as a usual nurse. In such situations, Ineed at least several hours to regain my ability to effectively perform my tasks and provide quality patient care (P.15).

Sometimes, I'm tired from household or childrearing activities. Such tiredness negatively affects my ability to provide quality care and makes me miss some aspects of patient care. Surely, such kind of practice violates the principles of ethical practice and hence, makes me feel unhappy (P. 8).

\subsubsection{Greater Incidence of Errors}

According to most participants, nurses should provide quality patient care, irrespective of their personal problems, because any shortcoming in care provision may result in nursing errors, negatively affect treatment outcomes, and prolong the course of treatment.

Sometimes, I am unable to concentrate on patient care because of my mother's ailment. Such familial problems can affect all of your activities. For instance, you may commit errors in writing patient Kardex or performing an injection. As a real example, some days ago, I was the charge nurse in the shift. At the beginning of the shift, my colleague entered the ward with sadness. She cried and said that her mother had gotten diabetes and was worried about that. Then, we went to administer patient medications. She erroneously gave an intravenous push of potassium chloride to a patient and I quickly called the doctor (P. 11).

\subsection{Low Care-Providing Morale}

The second main theme of the study was low careproviding morale. Some participants had sought em- 
ployment due to its probable positive outcomes, such as greater independence, self-efficacy, and social contribution. However, poor work conditions and difficult familial problems had made them think about leaving the profession and changing their career, develop disinterest in nursing, and feel tired and exhausted at work. The two subthemes of this main theme were poor job motivation and job dissatisfaction.

\subsubsection{Poor Job Motivation}

4.2.1.1. Intention to Leave the Profession

Due to their heavier responsibilities compared with other professions, some participants had decided on leaving nursing.

I had a small baby during my first three years of hospital work. Both of us experienced difficulties in that period. Once my second child was born, I completely quit my job in order to rear my children. (P. 5).

\subsubsection{Disinterest in Nursing}

Daily work-related and familial problems had resulted in disinterest in nursing for some participants.

One day, I had poor psychological conditions. That day, we had a critically-ill patient in the ward, whose family members imposed great pressure on us, made us nervous, and even threatened us. That they, I felt so severe psychological strain that I did not like to enter the hospital for one week (P.1).

\subsubsection{Feelings of Fatigue and Exhaustion}

Most participants had experienced great fatigue and felt greatly non-energetic due to their familial problems and their effects on their work and hence, felt little professional efficacy.

With a work experience ofjust five years, I currently feel that I'm psychologically tired. I really feel what is called job burnout. Ifeel I'm too tired (P.14).

\subsubsection{Job Dissatisfaction}

Participants experienced great stress and strain due to their heavy familial responsibilities. On the other hand, they had little time for their families due to their numerous work shifts. Besides, their financial concerns and strains had caused dissatisfaction for themselves and their families.

\subsubsection{Financial Problems}

Participants experienced different financial problems. If they don't pay your salary for several consecutive months, you will have no more motivation for work. When they don't pay you, you may think at work why you should continue working, experience financial strain, and putyourfamily under pressure.
Without payments, you are dissatisfied, disinterested in working, and feel tired and non-energetic (P.12).

\subsubsection{Numerous Work Shifts}

One of the participants referred to the negative effects of numerous work shifts.

Most nurses are dissatisfied because they are working below the minimum standards of work. Numerous work shifts and heavy workload result in dissatisfaction. In non-standard conditions, you need to do numerous shifts and hence, experience physical and psychological fatigue. Contrarily, standard work conditions can improve nurses' job satisfaction (P. 3).

\subsubsection{Lack of Recreational Opportunities for Nurses and Their} Families

Participants were also dissatisfied with the inadequacy of recreational opportunities for nurses and their families.

The authorities need to avoid focusing on our weaknesses. Rather, they should reinforce the positive aspects of our performance. They should give us positive energy. They should provide us with recreational activities. For example, they can invite us to a public place to eat dinner together with our other colleagues and their families. We need humor and recreation. Instead of extensive criticisms, they need to provide their staff with the opportunities for doing physical exercise (P. 9).

\subsection{Damages to Professional Relationships}

Participants frequently faced different challenges in establishing professional relationships with patients and their colleagues due to unrealistic familial and professional expectations.

\subsubsection{Challenges in Establishing Relationships with Patients}

Most participants noted that their preoccupation with familial problems prevents them from establishing effective relationships with patients and fulfilling patients' needs. According to them, these problems result in patients' poor collaboration with nurses as well as stress for both patients and nurses.

\subsubsection{Improper Conduct Towards Patients}

One of the participants referred to the effects of familial problems on their conduct towards patients and care quality.

A familial problem might have caused you tiredness or you may have a financial problem. These problems can negatively affectyour relationships with your patients though you attempt to control them. For example, a patient may frequently askyou questions and you may answer him/her in a bad manner due to familial problems (P. 6). 
4.3.1.2. Tensions in Relationships with Patients' Family Members

Nurses' familial problems may also result in tensions in their relationships with patients' family members.

We had a seriously-ill patient in ourward while I was preoccupied with my child, who frequently called me from home and complained about having fever. It was in the visitation time and there were many family members in the ward. They frequently asked us different questions. Meanwhile, the conditions of that seriously-ill patient became worse. I entered into dispute with family members and called the security staff of the hospital to manage the situation (P.4).

\subsubsection{Problems in Establishing Relationships with Other Hospi-} tal Workers

Familial problems may also negatively affect nurses' relationships with other hospital workers.

\subsubsection{Tensions in Relationships with Colleagues}

Nurses with familial problems may experience tensions in their relationships with their colleagues.

If I entered into a dispute with my colleagues, they understood that I had had some problems at home (P. 5).

\subsubsection{Poor Relationships with Physicians}

Participants also noted that their familial problems occasionally affect their relationships with physicians.

I had a problem and hence, I was in no mood for talking with anyone. That day, when the doctor asked me a request, I answered him so badly that it resulted in a dispute between us. Finally, I was obliged to change my ward (P. 10).

\section{Discussion}

This study explored the effects of nurses' family-work conflict on patient care quality. Findings revealed that familial problems had caused nurses different difficulties and concerns over care provision.

Reduced mental ability for care provision was one of the main effects of nurses' familial problems on their work. Most participants highlighted that family-work conflict places great strain on them, reduces their concentration and preciseness at work, and thereby, negatively affects the quality of their care services. In line with these findings, an earlier study reported that family-work conflict is associated with different negative outcomes for nurses, such as physical and mental fatigue, emotional strain, poor professional performance, increased likelihood of nursing errors, and reduced ability for quality care provision (17). Another study on nurses at five hospitals in Taiwan also revealed that work-family conflict negatively affected nurses' professional practice (18). Thereby, it can also result in great likelihood of nursing errors (19). Similarly, a cross-sectional study on 219 female and 201 male physicians in Hungary revealed family-work conflict as a significant stressor for them, which negatively affected the quality of their care services (20). Another cross-sectional study on Chinese female nurses indicated that family-work conflict reduced their professional efficacy (21).

The second main effect of family-work conflict on nurses was low care-providing morale. The current participants noted that high levels of their professional accountability, patients' frequent questions and requests, and hospital authorities' frequent criticisms created difficult work conditions for them and reduced their ability for fulfilling patient needs and professional responsibilities. Consequently, they were bored and disinterested in their work, felt dissatisfied with their work, and decided on leaving it. Similarly, an empirical study revealed that nurses' familial problems can result in professional problems, reduced job satisfaction, and increased likelihood of leaving the profession (22). Moreover, work-family conflict was found in another study to have a negative relationship with job satisfaction and life satisfaction and a positive relationship with intention to leave the profession (23). A study on nurses in China also reported that work-family imbalance may finally require nurses to leave their profession (24).

The other main effect of family-work conflict was damages to professional relationships. The study findings indicated that nurses' preoccupation with familial problems negatively influenced their relationships with their colleagues, patients, and patients' family members. In agreement with these findings, a study from Italy showed that family-work conflict has negative effects on nurses' functional communication and professional relationships (25). A review study also showed that family-work conflict had negative effects on interpersonal relationships (8). Another study also revealed that nurses' occupational stress and physical and mental exhaustion weakened their professional relationships, increased their turnover, reduced their ability to fulfill their professional responsibilities, and impaired their professional performance (26).

\subsection{Conclusion}

Family-work conflict is associated with different negative outcomes for nurses, mainly including reduced mental ability for care provision, low care-providing morale, and damages to professional relationships. Nursing managers can use the findings of this study to improve patient care quality through developing appropriate strategies for nurses' job enrichment, job rotation, and in-service continuing education about stress management, time management, and conflict management. 


\section{Acknowledgments}

The authors would like to thank Birjand University of Medical Sciences, Birjand, Iran, for financially supporting this study. Moreover, they are thankful to all nurses, who participated in the study.

\section{Footnotes}

Authors' Contribution: Study design for this article is conducted by Ahmad Nasiri. Data collection and analysis is performed by Ahmad Nasiri, Sommaye Namdari, Samaneh Nakhaee and Fatemeh Taheri. Preparation of manuscript is performed by Sommaye Namdari.

\section{Ethical Considerations: IR.BUMS.REC.1396.163}

\section{References}

1. Calvo-Salguero A, Martinez-De-Lecea JM, Carrasco-Gonzalez AM. Workfamily and family-work conflict: Does intrinsic-extrinsic satisfaction mediate the prediction of general job satisfaction? J Psychol. 2011;145(5):435-61. doi:10.1080/00223980.2011.584082. [PubMed: 21902011].

2. Carlson DS, Grzywacz JG, Zivnuska S. Is work-family balance more than conflict and enrichment? Hum Relat. 2009;62(10):1459. doi: 10.1177/0018726709336500. [PubMed: 20148121]. [PubMed Central: PMC2818261].

3. Alhani F, Oujiyan P. Work-family conflict among nurses and its relation to their quality of life. J Ethics Educ. 2013;2(1):46-55.

4. Eshak ES, Kamal NN, Seedhom AE, Kamal NN. Work-family conflict and self-rated health among dwellers in Minia, Egypt: Financial strain vs social support. Public Health. 2018;157:69-76. doi: 10.1016/j.puhe.2018.01.016. [PubMed: 29500946].

5. Charkhabi M, Sartori R, Ceschi A. Work-family conflict based on strain: The most hazardous type of conflict in Iranian hospitals nurses. SAJ Indust Psychol. 2016;42(1):1-10. doi: 10.4102/sajip.v42i1.1264.

6. Hao J, Wang J, Liu L, Wu W, Wu H. Perceived organizational support impacts on the associations of work-family conflict or family-work conflict with depressive symptoms among Chinese doctors. Int J Environ Res Public Health. 2016;13(3). doi: 10.3390/ijerph13030326. [PubMed: 26999175]. [PubMed Central: PMC4808989].

7. Mozafari M, Azami G, Lotfizadeh Dehkordi M, Aazami S. Validation of multidimensional Persian version of the work-family conflict questionnaire among nurses. Int J Occup Environ Med. 2016;7(3):164-71.

8. Almost J. Conflict within nursing work environments: Concept analysis. J Adv Nurs. 2006;53(4):444-53. doi: 10.1111/j.1365-2648.2006.03738.x. [PubMed: 16448487].

9. Gurbuz S, Turunc O, Celik M. The impact of perceived organizational support on work-family conflict: Does role overload have a mediating role? Econ Indust Democracy. 2013;34(1):145-60. doi: $10.1177 / 0143831$ X12438234.

10. Allen TD, Herst DE, Bruck CS, Sutton M. Consequences associated with work-to-family conflict: A review and agenda for future research.J Occup Health Psychol. 2000;5(2):278-308. [PubMed:10784291].
11. Bagherzadeh R, Taghizadeh Z, Mohammadi E, Kazemnejad A, Pourreza A, Ebadi A. Relationship of work-family conflict with burnout and marital satisfaction: Cross-domain or source attribution relations? Health Promot Perspect. 2016;6(1):31-6. doi: 10.15171/hpp.2016.05. [PubMed: 27123434]. [PubMed Central: PMC4847112].

12. Cortese CG, Colombo L, Ghislieri C. Determinants of nurses' job satisfaction: The role of work-family conflict, job demand, emotional charge and social support. J Nurs Manag. 2010;18(1):35-43. doi: 10.1111/j.1365-2834.2009.01064.x. [PubMed: 20465727].

13. Killien MG. Nurses' health: Work and family influences. Nurs Clin North Am. 2004;39(1):19-35. v. doi:10.1016/j.cnur.2003.11.002. [PubMed: 15062725].

14. Manouchehri H, Imani E, Atashzadeh-Shoorideh F, Majd HA. [Challenges of work during studying from the perspective of nurses: A qualitative study with content analysis approach]. Koomesh. 2017;19(2). Persian.

15. Graneheim UH, Lundman B. Qualitative content analysis in nursing research: Concepts, procedures and measures to achieve trustworthiness. Nurse Educ Today. 2004;24(2):105-12. doi: 10.1016/j.nedt.2003.10.001. [PubMed:14769454].

16. Elo S, Kaariainen M, Kanste O, Polkki T, Utriainen K, Kyngas H. Qualitative content analysis: A focus on trustworthiness. SAGE Open. 2014;4(1):1-10. doi: 10.1177/2158244014522633.

17. Grzywacz JG, Frone MR, Brewer CS, Kovner CT. Quantifying work-family conflict among registered nurses. Res Nurs Health. 2006;29(5):414-26. doi: 10.1002/nur.20133. [PubMed: 16977647].

18. Wang ML, Tsai LJ. Work-family conflict and job performance in nurses: The moderating effects of social support. J Nurs Res. 2014;22(3):200-7. doi: 10.1097/jnr.0000000000000040. [PubMed: 25111113].

19. Pani JR, Chariker JH. The psychology of error in relation to medical practice. J Surg Oncol. 2004;88(3):130-42. doi: 10.1002/jso.20123. [PubMed: 15562465].

20. Ádám S, Győrffy Z, László K. High prevalence of job dissatisfaction among female physicians: Work-family conflict as a potential stressor. Clin Exp Med J. 2009;3(3):453-61. doi: 10.1556/CEMED.3.2009.28582.

21. Wang Y, Chang Y, Fu J, Wang L. Work-family conflict and burnout among Chinese female nurses: The mediating effect of psychological capital. BMC Public Health. 2012;12:915. doi: 10.1186/1471-2458-12-915. [PubMed: 23107113]. [PubMed Central: PMC3585697].

22. Unruh LY, Raffenaud A, Fottler M. Work-family conflict among newly licensed registered nurses: A structural equation model of antecedents and outcomes. JHealthc Manag. 2016;61(2):129-45. [PubMed: 27111932].

23. Mazerolle SM, Bruening JE, Casa DJ, Burton LJ. Work-family conflict, part II:Job and life satisfaction in National Collegiate Athletic Association Division I-A certified athletic trainers. J Athl Train. 2008;43(5):51322. doi: 10.4085/1062-6050-43.5.513. [PubMed: 18833314]. [PubMed Central: PMC2547871].

24. Yamaguchi Y, Inoue $\mathrm{T}$, Harada $\mathrm{H}$, Oike M. Job control, work-family balance and nurses' intention to leave their profession and organization: A comparative cross-sectional survey. Int J Nurs Stud. 2016;64:52-62. doi: 10.1016/j.ijnurstu.2016.09.003. [PubMed: 27689509].

25. Camerino D, Sandri M, Sartori S, Conway PM, Campanini P, Costa G. Shiftwork, work-family conflict among Italian nurses, and prevention efficacy. Chronobiol Int. 2010;27(5):1105-23. doi: 10.3109/07420528.2010.490072. [PubMed: 20636219].

26. Khaghanizade M, Salimi SH, Rahmani R. . Congress of Military Medicine. 2002. Persian. 